\title{
An Assessment on Food Safety of Takeout Pho in Vietnamese Restaurants
}

Helen Wang ${ }^{1}$, Vanessa Karakilic ${ }^{2}$, Lorraine McIntyre ${ }^{3}$

1 Lead Author, B. Tech Student, School of Health Sciences, British Columbia Institute of Technology, 3700 Willingdon Ave, Burnaby, BC V5G 3H2

2 Supervisor, School of Health Sciences, British Columbia Institute of Technology, 3700 Willingdon Ave, Burnaby, BC V5G

$3 \mathrm{H} 2$

3 Contributor, British Columbia Centre for Disease Control, $655 \mathrm{~W} 12^{\text {th }}$ Ave, Vancouver, BC V5Z 4R4

\begin{abstract}
Background and Purpose: Foodborne illness associated expenditures cost the health care system an estimate of $\$ 100$ million per year (1). Although the best approach in handling foodborne illnesses is through prevention, it becomes a challenge when it involves choosing between food associated risk or food quality. Take out pho (traditional Vietnamese noodle soup) poses a significant food safety concern when the raw beef and broth are packaged separately. The decreasing temperature of the broth presents a questionable critical control step. If the raw beef is not properly cooked, potential pathogens like E.coli can survive and cause foodborne illness. The following study examines the risk of foodborne illnesses associated with takeout pho and determines whether the broth can achieve an adequate temperature of $70^{\circ} \mathrm{C}$ to completely pasteurize the raw beef after twenty minutes.

Methods: Thirty samples of takeout pho were collected from thirty Vietnamese restaurants within Vancouver and Burnaby, BC. Statistical analysis was performed using a Z-test to compare the median mixed temperature with the cooking standard of $70^{\circ} \mathrm{C}$ using a Z-test after twenty minutes.

Results: Based on the results, the median pho temperature was $62.25^{\circ} \mathrm{C}$ with a standard deviation of $6.69^{\circ} \mathrm{C}$. The range was $30.3^{\circ} \mathrm{C}$ with the minimum temperature of $42.7^{\circ} \mathrm{C}$ and the maximum temperature of $73^{\circ} \mathrm{C}$. The mode was $62.5^{\circ} \mathrm{C}$. The results generated a $\mathrm{p}$-value of $<0.0001$.

Conclusions: The median temperature of the thirty samples did not achieve the cooking standard temperature of $70^{\circ} \mathrm{C}$. Thus, the temperature of the broth cannot be considered a critical control step after twenty minutes from the time of pick up. Improper food handling and time-temperature abuse can introduce and support the growth of pathogens on raw beef which naturally has E.coli. Therefore, this can increase the possibility of consuming pathogens from undercooked beef causing an increased risk of foodborne illnesses. Pasteurization using time and temperature combination can potentially remove the risk however, there is not enough food handling instructions provided for the consumer to properly cook the raw beef to a safe temperature. Implications for policy development designed for Environmental Health Officers to educate and raise awareness in respect to takeout pho should be considered.
\end{abstract}

Key words: Takeout; take away; pho; foodborne illness; Vietnamese; raw beef 


\section{INTRODUCTION}

Each year, 1 in 8 Canadians (4 million people) will get sick from consuming contaminated food (2). Of the 4 million people infected, 11,600 will require hospitalization and 238 will die (3). Of the 31 known pathogens to cause foodborne illnesses, Norovirus, Salmonella (nontyphoidal), Clostridium perfringens, Campylobacter species., Staphylococcus aureus, Toxoplasma gondii, Escherichia coli O157, and Listeria monocytogenes are responsible for the vast majority of illnesses, hospitalizations, and deaths (4). Foodborne illnesses are costing the economy an estimate of $\$ 100$ million per year, with addition to 19.7 million sick days (1). Foodborne illnesses are frequent, costly yet preventable public health issue.

The best approach in handling foodborne illnesses is through prevention. However, it is a challenge when it comes to choosing between food associated risk or food quality. In the case of pho, a traditional Vietnamese noodle soup consisting of rice noodles and raw beef slices in a clear broth, the raw beef is considered a delicate ingredient regardless of the associated risk. Fortunately, the submersion of raw beef in the broth provides a kill step, should pathogens be present. Furthermore, it allows consumers a unique way of cook the beef according to their liking.

It is generally not a problem when pho is consumed at a restaurant as long as it is handled safely, but when it is allowed to be taken home, it introduces a significant food safety concern due to a lack of control of what consumers do with it. Takeout pho is packaged separately, two containers are used, one to hold noodles and raw beef, and the other to hold broth. However, because the pho is not consumed right away, the temperature of the broth dramatically decreases between the time of pick up to the time of consumption; this ultimately decides whether it can adequately cook the raw beef hence, destroying the potential presence of pathogens on the beef.

As time passes, the decreasing temperature of the broth is becoming less of a critical control step. With an inadequate critical control step, the potential for foodborne illness greatly increases. As a result, it is important to evaluate the final temperature of the broth with the noodles as this will indicate the risk of consuming undercooked beef hence, a potential exposure to pathogens from the undercooked beef. Therefore, the purpose of this study is to evaluate whether it is safe to allow Vietnamese restaurants to provide raw beef and pho soup for customers to take home. This issue was introduced by Lorraine McIntyre from the British Columbia Centre for Disease Control.

The purpose of the evidence review is to explore the current literature that examines the factors that can influence takeout food safety. Furthermore, as takeout food is becoming an increasing trend, this review will consider implications for policy development in respect to takeout food safety.

\section{EVIDENCE REVIEW}

In order to evaluate the food safety of takeout foods, it is necessary to take into account the possible factors that can introduce and support the growth of pathogens on the food. Factors include the food handling practices at restaurants, general food safety knowledge of operators and consumers, and the prevalence of contaminated beef. Additionally, consumer takeout trends, properties of takeout containers, and roles of Environmental Health Officers (EHO) will also be discussed in the evidence review.

\section{Improper food handling practices}

Foodborne illness is defined as a disease caused by consuming food or drink that has been contaminated with a particular type of bacteria, virus, mould or parasite (5). Improper food handling has been identified to be a major cause of foodborne illness. Although, most food naturally harbours bacteria, it can become hazardous when bacteria are allowed to survive and multiple to a dangerous level. During thawing process, if the food is left at an ideal temperature for a considerable amount of time $(>4$ hours), the bacterial level can multiple significantly, increasing the likelihood of foodborne illness (5). This is a common improper food handling practice that is often seen in restaurants and homes thus, it contributes as a factor for assessing food safety in takeout food, especially for pho (6).

\section{Knowledge of food safety among restaurant employees}

In order to follow and apply proper food handling practices, food handlers require necessary 
knowledge and skills to enable such application. However, it was not until July 29, 2013 that FOODSAFE Level 1 certificates were mandated to be renewed every five years in British Columbia. Prior to July, 29, 2013, operators with FOODSAFE Level 1 certificates were not required to refresh their food safety knowledge (7). Manes and colleagues (8) discovered many food handlers reported to have never taken food safety training courses or received any food safety training at work. Consequently, the questionaries' reflected some knowledge gaps related to optimal temperature for cooking, holding and refrigeration, cross contamination, and hygiene.

A study was conducted by Grujic and colleagues (9) also found that employees were unfamiliar with basic food safety such as when not to work and how to tell if food has been contaminated. Although employees were indeed aware of the presence of sanitary and infrastructure conditions that could hinder the delivery of safe food, barriers such as employees' mood, lack of motivation, and rapid employee turnover were attributing factors that limit the practical implementation of HACCP in restaurants $(10)$.

\section{Knowledge of food safety among consumers}

Food safety knowledge does not only apply in food establishments but also to the consumer. Numerous government websites provide information to educate the public on safe food handling. Canadian Partnership for Consumer Food Safety Education established simple steps (Clean, Separate, Chill and Cook) to reduce home associated foodborne illnesses (5). Despite the provided information, only $67 \%$ of people always washed their hands prior to eating or handling food, $60 \%$ of people did not know the recommended refrigeration temperature, and $14 \%$ of people used a thermometer to determine when meat was cooked thoroughly (11). Improper food handling practices, lack of food safety knowledge, and poor hygiene at home attributes to an overall of $21 \%$ of foodborne illness outbreaks (12). While takeout food is generally consumed as soon as possible, consumers still admitted to not being as knowledgeable about food safety and handling as they would like (13).

\section{Prevalence of pathogens on beef}

As part of accessing takeout pho food safety, it is important to examine how often contamination occur within processing plants. Salmonella enterica, Escherichia coli O157:H7 and Shigella spp. are the major pathogens associated with meats and dairy products (14). Ahmed and colleagues (14) found the presence of E. coli O157:H7 was more of a concern in dairy products rather than in meat products. On the other hand, a study by Barkocky-Gallagher and colleagues (15) discovered that non-O157 Shiga toxin-producing E. coli serotypes are more prevalent in beef products than E. coli O157:H7. In 2000 to 2006, there was a steady increase of reported cases in non-O157 Shiga toxin-producing E. coli, reflecting in an overall of four-fold increase in incidence $(0.12$ cases per 100,000 to 0.42 cases per 100,000 population) (16).

In addition to the innate presence of pathogens on beef and potential contamination from food handlers, pathogens can also be introduced through food processing equipment. Meat tenderizers and meat slicers are some commonly contaminated food processing equipment (17). For example, the largest meat recall in Canadian history involved XL Foods recalling more than 1.8 million kilogram of mechanically tenderized beef in 2013 (18). Another well known example was the Maple Leaf Foods outbreak where the meat slicer contaminated the deli meat resulting in twenty deaths throughout Canada in 2008 (19).

\section{Safe internal temperatures and required holding times}

Government sites and BCCDC provide guidelines for time - temperature criteria targeted for conventional cooking however, there is limited information on cooking practices outside of conventional cooking (20). Sous vide pasteurization of food is a cooking method performed under water in a vacuum package and cooked at lower temperatures for a specified period of time. Unlike conventional standards of cooking, the process of sous vide pasteurization is strictly reliant on both time and temperature (20). In hopes of achieving a minimum of $6.5-\log 10$ reduction in meats, the internal core temperature of the food must be at equilibrium with the water and maintained for the specified amount of time for full sous vide 
pasteurization (21). In relation to raw beef in takeout pho, the concept of sous vide pasteurization applies. Once the noodles and broth reaches equilibrium, the raw beef must be held for a specified holding time, which is dependent on the temperature of the broth. To achieve uniform cooking and to prevent undercooking, it is best to fully submerge the beef in the broth (22).

\section{Takeout trend and legislation}

According to Statistics Canada, the number of food and beverage establishments increased to nearly 79,000 nationwide, with the largest increase from fast food restaurants in 2009 (23). There is a continuous demanding need for convenience that is reflected by the increasing trend in consumer spending at food service establishments (23).

Takeout food is generally for immediate consumption with factors such as location, time and convenience impacting decisions for purchase (24). As the desirability for takeout continues to grow, consumers prefer takeout containers to be able to insulate the food, to contain product without spillage, and to keep individual foods separate within the same package (25). Regardless of the desirable characteristics for takeout containers, it lacks handling instructions for consumers. Unlike Australia, restaurants in Canada are not required to provide any handling instructions for consumers (26). Figure 1 illustrates the information found on takeout containers in Australia (26). The Australian guideline informs customers on how to safely handle their takeout food with the inclusion of their temperature requirements.

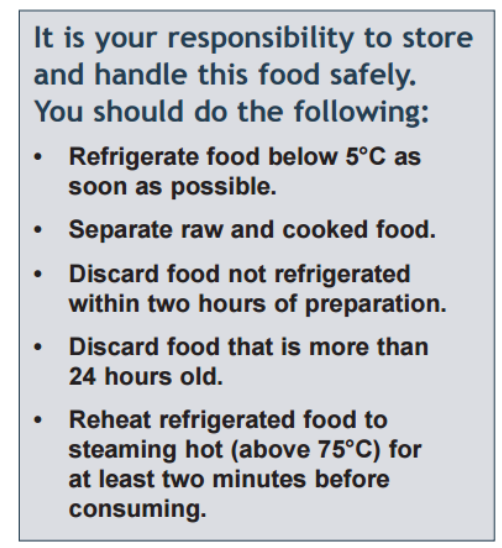

Figure 1: Australian guidelines for takeout food safety provided on takeout containers

\section{Polypropylene versus Expanded Polystyrene foam takeout containers}

The construction quality and material of takeout containers are critical for insulation. Consumers express the importance of food containers that allow storing and reheating of food in their original container (27). Expanded polystyrene foam (Styrofoam) containers are light weight and have good thermal insulation and shock absorption properties, which might suggest why it is the most common takeout container used (27). However, expanded polystyrene foam is neither recyclable, reusable, compostable or biodegradable $(27,28)$. As consumers are more aware of the environmental impacts, trends towards recyclable, reusable, and sustainable containers are making its way to major restaurants (27). In fact, most Vietnamese restaurants have switched from using expanded polystyrene foam containers to polypropylene containers. According to Canada's Food and Drugs Act, plastic food containers that are not sold with food are not tested by Health Canada and there are no guidelines that prohibit what substances can be used $(29,30)$.

Nowadays, the prominent takeout containers are made with polypropylene. It is lightweight, durable, highly resistant to chemicals and temperature and much more environmental friendly (27).

Furthermore, it is also microwavable (29). But most importantly, polypropylene containers have not been determined to be associated with health impacts, whereas studies suggest polystyrene may be a possible carcinogen (28). In respects to takeout pho, the ability to be able to microwave the container is very important. With the polypropylene containers, consumers can easily reheat the broth using microwaves therefore, a potential inconvenience barrier is eliminated.

\section{Roles of Environmental Health Officers (EHO)}

EHOs are responsible for protecting public health through the use of education, persuasion and enforcement. With the rising trend for takeout food, the absence of handling instructions in addition to consumers' inadequate food safety knowledge, a greater risk of foodborne illness is presented. Under 
the Public Health Act, EHOs are mandated to inspect food service establishments. Inspections allow for education and correction of improper food handling practices. By changing food handling behaviours, this reduces the risk and likelihood of contaminating and supporting the growth of microbes within restaurants. Although, the new FoodSafe course advises operators that it is their responsibility to remind customers on the proper storage and reheating of their leftover or takeout food, this implementation is seldom seen in restaurants (Instructor Vanessa Karakilic, personal communication at BCIT, 2015 January). Thus, consumers must be educated and well informed in basic food safety such as not leaving food at room temperature. Perhaps, EHOs can provide input for developmental policy regarding takeout food safety in the future.

\section{Conclusion}

Based on the evidence review, there has been extensive studies conducted on food handling issues and food safety knowledge in food handlers but not enough studies pertaining to takeout food safety. As the takeout food trend is increasing, takeout food is becoming an important factor when it comes to addressing foodborne illness issues. This is especially important when it comes to assessing food safety in potentially hazardous takeout foods such as pho. The evidence review discussed factors that influence takeout food safety such as common improper food handling practices, food safety knowledge among operators and consumers, prevalence of contaminated beef, characteristics of takeout containers, and required holding times to acquire sufficient reduction of pathogens.

It is important to understand that each factor contributes to the possibility of introducing, supporting and eliminating the presence of pathogens on food. Thus, the prevention of foodborne illness relies on each and every factor to minimize the risks for consumers. There are regulations, guidelines, codes and EHOs to educate and assist restaurant operators with safe food handling in food establishments. Additionally, government sites such as Health Canada, Canadian Food Inspection Agency, BC Centre for Disease Control, and Canadian Partnership for Consumer Food Safety provide information on safe food handling for consumers at home. For policy development regarding promotion of healthy Canadians or food safety, consideration of takeout food is necessary.

Take out pho is particularly risky, if the raw beef is contaminated or temperature abused at the restaurant, consumers are potentially increasing risk of foodborne illness if the final cook temperature is not achieved. The broth is the only kill step that can destroy pathogens on the beef. Nonetheless, if the temperature is not adequate, the pathogen will survive. Currently, it is up to the consumer's judgement whether to reheat the broth or not.

\section{PURPOSE OF THE STUDY}

There is limited information on foodborne illnesses associated with pho, a potentially hazardous food. Factors such as the lack of food safety knowledge, time-temperature abuse, and the absence of a lethal kill step can contribute to the increased risk of foodborne illnesses from pho. Therefore, the purpose of this research project is to monitor the temperature of pho broth in takeout containers and to determine whether the temperature can still be considered a "kill step" once the broth is poured over the noodles.

\section{METHODS AND MATERIALS}

The researcher visited 30 Vietnamese restaurants in Vancouver and Burnaby, BC and bought a small bowl takeout pho with rare beef slices from each restaurant. Jekanowski and colleagues (31) discovered that most consumers are only willing to travel an average time of fifteen minutes to purchase takeout food. This study included an extra five minutes to address potential unfavorable traffic conditions that some consumers may face.

Therefore, the total duration for each sample was twenty minutes.

The thermocouple was calibrated using ice bath and boiling water prior to recording the samples. Once the takeout pho arrived, the researcher inserted the thermocouple probe into the broth and the initial temperature reading was recorded. After twenty minutes, the thermocouple probe was inserted into the broth to record the final temperature reading. The broth was poured over the noodles and mixed using chopsticks. The mixed temperature reading was 
recorded. The temperature of each sample was measured using Digi-Sense Duallog R thermocouple thermometer (Model No. 91100-50).

\section{RESULTS}

Temperature of pho broth in the takeout containers and the final mixed noodle and broth temperature were collected. The null and alternative hypothesis were:

Null Hypothesis: $\mu \geq 70^{\circ} \mathrm{C}$

Alternative Hypothesis: $\mu<70^{\circ} \mathrm{C}$

The null hypothesis suggests that median temperature of the takeout pho broth with noodles can maintain a temperature of $70^{\circ} \mathrm{C}$ and above after twenty minutes. Whereas, the alternative hypothesis suggests that temperature of takeout pho broth with noodles cannot maintain the cooking standard of $70^{\circ} \mathrm{C}$ after twenty minutes. This proposes an idea that takeout pho may not be "safe for consumption" in terms of food safety after twenty minutes since there is no guaranteed kill step. In contrast, if the null hypothesis is true then, this provides information that takeout pho that falls within an average travel time of twenty minutes from the time of pick up to the time of consumption may pose limited risk to foodborne illness.

This study collected continuous numerical data as temperature is a measurement on a continuum (32). The obtained temperature data of 30 pho samples were analyzed for statistical significance.

\section{Collected Data}

Table 1 illustrates the recorded temperatures from the 30 takeout pho samples obtained from the 30 different Vietnamese restaurants. Descriptive statistics were generated for initial and mixed temperature.
Table 1: Temperature readings of takeout pho samples collected from 30 different Vietnamese restaurants.

\begin{tabular}{|c|c|c|c|}
\hline Vietnamese Restaurants & Initial Temperature $\left({ }^{\circ} \mathrm{C}\right)$ & Final Temperature $\left({ }^{\circ} \mathrm{C}\right)$ & Mixed Temperature $\left({ }^{\circ} \mathrm{C}\right)$ \\
\hline 1 & 90.1 & 79.1 & 54.2 \\
\hline 2 & 84.7 & 73.9 & 60.3 \\
\hline 3 & 83 & 74.6 & 61.5 \\
\hline 4 & 45.1 & 42.3 & 42.7 \\
\hline 5 & 89.4 & 78.5 & 70.6 \\
\hline 6 & 92.5 & 80 & 54.5 \\
\hline 7 & 83.5 & 69.2 & 62 \\
\hline 8 & 94.2 & 81.1 & 63.2 \\
\hline 9 & 87 & 76.1 & 65.2 \\
\hline 10 & 84.8 & 76.4 & 66 \\
\hline 11 & 91 & 75.5 & 62.5 \\
\hline 12 & 94.3 & 84.5 & 73 \\
\hline 13 & 95 & 82.5 & 67.2 \\
\hline 14 & 90 & 77.6 & 66.9 \\
\hline 15 & 91.4 & 78 & 64.1 \\
\hline 16 & 94.1 & 83.9 & 67 \\
\hline 17 & 79.8 & 71.5 & 65.3 \\
\hline 18 & 90.6 & 77 & 65.5 \\
\hline 19 & 83.2 & 75.2 & 59 \\
\hline 20 & 93.2 & 80.9 & 64.5 \\
\hline 21 & 94.3 & 83.4 & 62.5 \\
\hline 22 & 85.3 & 76.3 & 50.8 \\
\hline 23 & 68.8 & 63.7 & 47.8 \\
\hline 24 & 93.8 & 78.5 & 61.8 \\
\hline 25 & 94.2 & 85 & 52.8 \\
\hline 26 & 82.1 & 72.8 & 57.8 \\
\hline 27 & 89.8 & 78.8 & 60.2 \\
\hline 28 & 86.7 & 75.5 & 60.1 \\
\hline 29 & 91.9 & 79.8 & 65 \\
\hline 30 & 85.2 & 74.3 & 54.8 \\
\hline
\end{tabular}

\section{Descriptive Statistics}

Table 2 is the descriptive statistics generated from the recorded initial temperature readings from the 30 samples. The results show that the mean temperature of the broth was $86.9^{\circ} \mathrm{C}$ with a standard deviation of $9.76^{\circ} \mathrm{C}$. The median temperature is $89.9^{\circ} \mathrm{C}$; the mode is $94.2^{\circ} \mathrm{C}$; and the range is $49.9^{\circ} \mathrm{C}$ with the maximum temperature of $95^{\circ} \mathrm{C}$ and the minimum of $45.1^{\circ} \mathrm{C}$. The range, median, and mode suggest the presence of an outlier. However, even in the presence of an outlier, the mean initial temperature of $86.9^{\circ} \mathrm{C}$ is still considered sufficiently hot. Based upon the recorded temperatures from all thirty samples, there is a decrease of approximately $10^{\circ} \mathrm{C}$ from initial temperature to final temperature after twenty minutes. Theoretically, this would suggest that the temperature of $86.9^{\circ} \mathrm{C}$ would drop to approximately $76^{\circ} \mathrm{C}$ after twenty minutes, which indicates that the temperature can still adequately cook the beef. But, once the broth is mixed with the noodles, there is a noticeable difference in temperature from $76^{\circ} \mathrm{C}$. This would indicate that other potential factors, other than the temperature of the broth play an important role in the food safety of takeout pho. 
Table 2: Descriptive statistical data on recorded initial temperature results

\begin{tabular}{lr}
\hline \multicolumn{2}{c}{ Initial Temperature } \\
\hline \multicolumn{2}{c}{} \\
Mean & 86.96666667 \\
Standard Error & 1.783012647 \\
Median & 89.9 \\
Mode & 94.2 \\
Standard Deviation & 9.765962471 \\
Sample Variance & 95.37402299 \\
Kurtosis & 11.62982142 \\
Skewness & -3.033613372 \\
Range & 49.9 \\
Minimum & 45.1 \\
Maximum & 95 \\
Sum & 2609 \\
Count & 30 \\
\hline
\end{tabular}

Table 3 is the descriptive statistics generated from the recorded mixed temperature readings from the 30 samples. The mean temperature of the broth is $60.96^{\circ} \mathrm{C}$ with a standard deviation of $6.69^{\circ} \mathrm{C}$. The median temperature is $62.25^{\circ} \mathrm{C}$; the mode is $62.5^{\circ} \mathrm{C}$; and the range is $30.3^{\circ} \mathrm{C}$ with the maximum temperature reading of $73^{\circ} \mathrm{C}$ and the minimum temperature reading of $42.7^{\circ} \mathrm{C}$.

The median temperature of $62.25^{\circ} \mathrm{C}$ suggests that the null hypothesis would be rejected therefore, stating that the median temperature of the thirty samples cannot achieve the cooking standard of $70^{\circ} \mathrm{C}$. This suggested that pho may not be safe for consumption after twenty minutes however, this conclusion may not be entirely true. The median temperature indicates that $50 \%$ of the readings lie above $62.25^{\circ} \mathrm{C}$ therefore time and temperature pasteurization is feasible in this situation. The mixed temperature of $62.25^{\circ} \mathrm{C}$ and above would only require a holding time of 5 minutes or less (20).

Table 3: Descriptive statistical data on recorded mixed temperature results

\section{Mixed Temperature}

Mean

Standard Error

Median
60.96

1.222091668

62.25
Mode

62.5

Standard Deviation

6.693671741

Sample Variance

44.80524138

Kurtosis

Skewness

0.839950624

Range

$-0.857023515$

Minimum

30.3

Maximum

42.7

Sum 73

1828.8

Count

30

\section{Inferential Statistics}

Z-test was performed to compare the mixed temperature of the samples to the cooking standard of $70^{\circ} \mathrm{C}$, the pasteurization temperature to cook raw beef suggested by BC Centre for Disease Control (20). The standard cut-off value of $p<0.05$ was applied. The collected temperatures were transferred from Microsoft Excel to NCSS for inferential statistical analysis.

\section{Interpretation of statistical results}

The data is not normally distributed according to Skewness Normality test (33). The p-value generated from the Wilcoxon Signed-Rank Test was $<0.0001$, which means the results are significant. As a result, the null hypothesis is rejected. The results support the alternative hypothesis in that the temperatures are significantly lower than the cooking standard.

\section{DISCUSSION}

According to section 10 of the Food Premise Regulation in pursuant to the Public Health Act, every operator and at least one employee present in the establishment must hold a FOODSAFE certificate or its equivalent (34). The purpose of a FOODSAFE certificate is to prevent the transmission of foodborne illnesses by ensuring food handlers are educated and trained on safe food handling practices (7). Proper food handling practices can prevent cross contamination, survival, and proliferation of microorganisms. The updated FOODSAFE course educates operators that food safety does not only apply within their establishment but also apply with their takeout foods as well (35). It is the responsibility of the establishment to ensure food is handled in a safe manner even when it leaves 
the premise. For example, to store takeout food in the refrigerator and to reheat to a temperature of $74^{\circ} \mathrm{C}$ (36). However, none of the thirty restaurants in this study gave any handling instructions to the researcher.

Since raw beef is served with takeout food, it is critical that the temperature of the broth maintains a minimum of $70^{\circ} \mathrm{C}$ to sufficiently cook the beef (20). If the broth cannot maintain the cooking temperature of $70^{\circ} \mathrm{C}$ when it is mixed with the noodles after twenty minutes, potential pathogens like E.coli on the raw beef cannot be destroyed. If consumed, this presents a risk of foodborne illness. In contrast, if the broth could maintain the cooking temperature of $70^{\circ} \mathrm{C}$ when it is mixed with the noodles after twenty minutes, any presence of potential pathogens could be destroyed. The 30 samples produced a median temperature of $62.25^{\circ} \mathrm{C}$, ranging from $42.7^{\circ} \mathrm{C}$ to $73^{\circ} \mathrm{C}$. Of the 30 samples, only two samples obtained a mixed temperature above $70^{\circ} \mathrm{C}$ thus, can be considered safe for consumption. Whereas, 28 of the 30 samples obtained a mixed temperature below $70^{\circ} \mathrm{C}$ and with one sample obtaining a recorded initial temperature of $42.7^{\circ} \mathrm{C}$, which did not even meet the required hot holding temperature of $\geq 60^{\circ} \mathrm{C}$ (20). The temperature of the broth can no longer sufficiently cook the raw beef however, it does not necessarily mean it is "unsafe for consumption".

Time and temperature pasteurization can be achieved if the temperature of the broth is less than $70^{\circ} \mathrm{C}$. Using time and temperature pasteurization, the average mixed temperature of $60.96^{\circ} \mathrm{C}$ would require a holding time of 8 minutes (20). However, the specified holding time is true only if the temperature remains constant. Therefore, taking into account the decreasing temperature of the broth, a holding time of at least 8 minutes is required to achieve pasteurization. Likewise, if the mixed temperature of the broth is $58.4^{\circ} \mathrm{C}$, it would require a holding time of more than 23 minutes to fully cook the raw beef (20). Based on a study conducted by United States Department of Agriculture (37), people aged 18 and over only spend a total of 67.8 minutes per day eating food, given 3 meals a day. Assuming a duration of 20 minutes is spent on each meal, this would indicate that the beef may still not cooked even after the meal is finished. Therefore, time and temperature pasteurization is realistically achievable at temperatures above $62.8^{\circ} \mathrm{C}$ with a holding time of at least 4 minutes (20). Of the 30 samples, $27 \%$ of the samples had a mixed temperature of $58^{\circ} \mathrm{C}$ and below. Operators should ensure the final mixed temperature can achieve a temperature of $62.8^{\circ} \mathrm{C}$ and above.

Prior to the use of polypropylene takeout containers, Vietnamese restaurants used Styrofoam containers. Polypropylene containers are biodegradable and microwave safe; this presents appealing and desirable characteristics for takeout use. However, the insulating property of Styrofoam containers far exceeds that of polypropylene containers (38). The ability of Styrofoam containers to retain heat for takeout pho may not present a food safety issue in the past. Unfortunately, based on this study, the reliance on the initial temperature of the broth using polypropylene containers can not determine whether the mixed temperature could cook the raw beef. For example, one sample recorded an initial temperature of $95^{\circ} \mathrm{C}$ and a mixed temperature of $66^{\circ} \mathrm{C}$ whereas, another sample recorded an initial temperature of $91^{\circ} \mathrm{C}$ and a mixed temperature of $73^{\circ} \mathrm{C}$. Although the first sample had a higher initial temperature compared to the second sample, once the noodles were introduced, the second sample had a higher mixed temperature in the end. The significant difference between $66^{\circ} \mathrm{C}$ and $73^{\circ} \mathrm{C}$ from sample one and two, respectively, indicates that the temperature of the noodles greatly impacts the final mixed temperature. Therefore, the noodles should be reheated prior to packaging for takeout.

Consumers have been posting amongst each other on Reddit and Yahoo Answers on what to do with the raw beef in takeout pho and whether it is safe to eat (39) (40). The majority of replies said to cook the beef in the broth and mix it in with the noodles (39) (40). Only one response addressed food safety concerns with raw beef such as time and temperature abuse and the importance of hot broth (40). This concern should be addressed by EHO's and food safety specialists.

Similar to pho, dishes such as beef takaki, yukhoe, and carpaccio are also serve with thinly sliced raw beef. Part of the preparation procedure is to freeze the whole cut to make it easier to cut thin slices. However, some but not all countries require the surface of the whole cut to be heat treated (41). Before Japan's new regulation, restaurants were only required to trim off the surfaces of whole cuts prior 
to serving raw beef dishes (41). Currently, the new regulation requires operators to heat treat the surface at least one-centimeter-deep at $60^{\circ} \mathrm{C}$ for at least two minutes followed by trimming one centimeter from each side (41) before serving the dish. A study conducted by Ethelberg et al (42) discovered that applying heat treatment on the surface can significantly reduce microbial infection without affecting the quality of the food. However, in BC, there are no requirements in the Food Premise Regulation or the BC Food Services Code to ensure operators follow this practice. Fortunately, this practice can be addressed in individual food safety plans.

To further exacerbate the problem, raw mung bean sprouts are served and packaged as condiments with pho. Similar to raw beef, the raw mung bean sprouts are reliant on the temperature of the broth to destroy potential pathogens like E.coli, Shigella, Yersinia enterocolitica, Bacillus cereus, Listeria monocytogenes and Salmonella (43). Raw beef and bean sprouts are both high risk foods that have been associated with many foodborne illness outbreaks (44). If bean sprouts are added to the noodles, there is an increased risk of foodborne illness. Therefore, reheating the broth is the best choice to ensure any potential pathogens from the raw beef or bean sprouts are destroyed.

\section{LIMITATIONS}

Due to the 20-minute time and budget constraints, the restaurants and samples were selected based on proximity to the researcher's home and not randomly selected. In addition, the temperature of the noodles was not considered however; it was discovered to greatly influence the final mixed temperature during the study. In terms of consistency, the amount of noodles was not the same, each restaurant provided different amount of noodles. Furthermore, some restaurants provided the noodles in a Styrofoam takeout box which required the researcher to transfer the noodles into an empty polypropylene container. The transfer could have further decreased the temperature of the noodles. As a result, this could have unintentionally reduced the temperature of the mixed broth. Moreover, this study did not consider the inclusion of bean sprouts and mint leaves which could further decrease the temperature of the broth.
The samples collected from each restaurant only provided a snap shot in time. The holding temperature of the broth from a restaurant could differ each day. In addition, the study cannot conclude whether the temperature of the broth before 20 minutes is safe since there are many factors that could influence the temperature of the broth. Lastly, there are no peer reviewed articles or studies on the food safety of takeout pho.

The study could be improved by selecting restaurants in a random manner. Randomization can eliminate any potential biases. Furthermore, to improve the reliability of the results, the researcher could increase the sample size by gathering multiple samples from the same restaurant and from additional restaurants. This could provide a representative data of restaurants in Vancouver. The researcher could have also measured the temperature of the noodles to determine how restaurants package takeout pho. In addition, this can allow the research to determine to what extent does the temperature of the noodles have an impact on the final mixed temperature. The researcher could ask for noodles and broth to be packaged in containers to prevent any deviation from the methods.

\section{RECOMMENDATIONS}

Reheating the noodles prior to packaging can substantially maintain a higher mixed temperature. As a result, time and temperature pasteurization might be achievable when the meat is fully submerged into the broth. In order to address the risk of foodborne illness associated with bean sprouts, operators could blanch the sprouts prior to packaging as well. The raw beef should not be stacked as this could prevent the beef from cooking evenly. The even distribution of beef on top of the noodles allow the broth to cook the surface of the beef when it is poured into the noodle container without the influence of the noodles. The Vietnamese restaurants could also sear the raw beef to reduce the likelihood of undercooking the beef while still providing the desired quality.

The development of food safety stickers on takeout containers could reduce the reliance on operators to remind consumers to reheat the food to the appropriate temperature of $74^{\circ} \mathrm{C}$ and increase food safety knowledge in consumers. As the trend towards take out food is increasing, the 
implementation of takeout food safety stickers may be the most cost-effective way to address the concerns with takeout pho and the potential for foodborne illnesses. As part of preventing foodborne illnesses, Environmental Health Officers are responsible for changing the behaviours of food handlers to avoid unsafe food handling practices through education and awareness of the potential risk associated with behaviours such as thawing raw meat in room temperature. Furthermore, reminders can be included in the yearly bulletin newsletters from health authorities and during routine inspections. Since the research suggests, there would be a food safety concern with pho, it would be important for EHO's to educate pho operators on the risk and have operators address the risk in their food safety plans. EHOs can educate and ensure operators understand their responsibility to provide safe food including takeout foods. Based on the findings, a provincial guideline for the safe preparation and serving of takeout pho would be beneficial to ensure consistency which can be similar to the guideline for donairs, and shawarmas.

\section{FUTURE RESEARCH}

1. To determine the effectiveness of time and temperature pasteurization, a study could be conducted by inoculating E.coli on the raw beef prior to pouring the broth over the noodles and then conducting a microbiological analysis to generate the remaining number of CFU of E.coli after undergoing time and temperature pasteurization. This method can be used to verify that pathogen reduction is observable and can justify the associated risk with takeout pho.

2. To determine the prevalence of consumers who do not reheat the broth, a survey could be conducted to determine the public perception on the safety of takeout pho and the reasons for not reheating the broth.

3. To further increase reliability and validity of the results obtained from this study, a subsequent study could be conducted by gathering more samples from the 30 selected Vietnamese restaurants. This will provide a better idea of the food safety with takeout pho since results will not be generated from grab samples that just provides a snap shot of time.

4. To measure the extent of temperature reduction as a result of adding noodles, a subsequent study could be conducted with the researcher requesting to have the noodles reheated prior to packaging and to compare the mixed temperature of the noodles with the results from this study.

5. To determine whether the implementation of takeout food safety stickers is effective in reducing foodborne illnesses, a survey could be conducted to monitor behaviour changes such as reheating the broth and to compare results with the number of foodborne illnesses associated with takeout food after the implementation of food safety stickers.

\section{CONCLUSION}

There are limited studies on the food safety of takeout food, especially on high risk foods such as the raw beef in pho. Fortunately, the updated FOODSAFE course addresses some of the takeout food safety issues by educating operators to remind consumers on what to do with the food when they get home. However, in this study, there is a notable lack of responsibility from operators and staff to remind their customers to reheat the broth to a temperature of at least $74^{\circ} \mathrm{C}$. The initial temperature of the broth can lead consumers to believe that the temperature of the broth can still adequately cook the raw beef by the time they get home. In order to determine whether it is safe for consumers to order raw beef pho for takeout from Vietnamese restaurants, the mixed temperature after twenty minutes was compared to the cooking standard of $70^{\circ} \mathrm{C}$. The 30 samples produced an average mixed temperature of $60.96^{\circ} \mathrm{C}$, which is far below the cooking standard of $70^{\circ} \mathrm{C} .50 \%$ of the samples were below the median temperature of $62.5^{\circ} \mathrm{C}$ and only two samples actually reached the adequate temperature. A temperature of $60.96^{\circ} \mathrm{C}$ cannot adequate destroy the potential presence of pathogens, resulting in foodborne illnesses. Furthermore, the lack of responsibility from the operators to remind customers to reheat the broth and the lack of food safety knowledge from the consumers can create more foodborne illnesses. While time and temperature pasteurization is applicable, it is not the most feasible choice. Based on the results from this study, takeout pho would be considered extremely risky when consumed without reheating the broth. The easiest and most effective 
method is to eliminate the risk of foodborne illness is by reheating the broth before eating.

\section{ACKNOWLEGEMENTS}

The authors thank Lorraine McIntyre for her suggestions on this topic and British Columbia Institute of Technology - Environmental Health for supporting this research.

\section{COMPLETING INTEREST}

The authors declare that they have no competing interests.

\section{REFERENCES}

(1) BC Center for Disease Control. Food Safety. 2015; Available at: http://www.bccdc.ca/healthinfo/food-your-health/food-safety

(2) Thomas MK, Murray R, Flockhart L, Pintar K, Pollari F, Fazil A, et al. Estimates of the burden of foodborne illness in Canada for 30 specified pathogens and unspecified agents, circa 2006. Foodborne Pathog Dis 2013;10(7):639-48.

(3) Government of Canada. Yearly food-borne illness estimates in Canada.2015; Available at:http://healthycanadians.gc.ca/eatingnutrition/risks-recalls-rappelsrisques/surveillance/illness-estimatesestimations-maladies/yearly-annuel-eng.php

(4) Centre for Disease Control. 2011 Estimates of foodborne illness in the United States. 2014; Available at:http://www.cdc.gov/foodborneburden/2011foodborne-estimates.html

(5) HealthLinkBC. Foodborne illness and safe food handling. 2014; Available at http://www.healthlinkbc.ca/healthtopics/content. asp?hwid=te4626

(6) BC Center for Disease Control. Writing your own food safety plan - the HACCP way. 2009; Available at: http://www.bccdc.ca/resourcegallery/Documents/Guidelines $\% 20$ and $\% 20$ Form s/Guidelines\%20and\%20Manuals/EH/FPS/Food/ EnsuringFoodSafetyHACCPWay.pdf

(7) FOODSAFE. Frequently asked questions. n.d.;Available at http://www.foodsafe.ca/main/faq

(8) Manes MR, Liu LC, Dworkin MS. Baseline knowledge survey of restaurant food handlers in suburban chicago: Do restaurant food handlers know what they need to know to keep consumers safe?. J Environ Health 2013; 76(1):18-26.

(9) Grujic S, Keran H, Vujadinovic D, Perusic M. Knowledge of employees in restaurants about the means and applications of HACCP. Quality of Life 2012; 3(3-4): 76-93.

(10) Grujic R, Antonic B, Brenjo D, Pavlovic P. Attitudes of workers employed in the restaurant toward importance of food safety system management implementation. Quality of Life 2013; 4(1-2): 5-11.

(11) Nesbitt A, Thomas MK, Marshall B, Snedeker $\mathrm{K}$, Meleta K, Watson B, et al. Baseline for consumer food safety knowledge and behaviour in Canada. Food Control 2014; 38:157-173.

(12) Centre for Disease Control. Tracking and reporting foodborne disease outbreaks. 2013; Available at:http://www.cdc.gov/Features/dsFoodborneOut breaks/? source $=$ govdelivery

(13) Boyce J, Broz CC, Binkley M. Consumer perspectives: take-out packaging and food safety. British Food Journal 2008;110(8):819 - 828.

(14) Ahemd AM, Shimamoto T. Isolation and molecular characterization of Salmonella enterica, Escherichia coli O157:H7 and Shigella spp. from meat and dairy products in Egypt. International Journal of Microbiology 2012; 168169:57-62.

(15) Barkocy-Gallagher GA, Arthur TM, RiveraBetancourt M, Nou X, Shackelford SD, Wheeler $\mathrm{TL}$, at el. Seasonal prevalence of Shiga toxinproducing Escherichia coli, including O157:H7 and non-O157:H7 serotypes, and Salmonella in commercial beef processing plants. J Food Prot 2003; 66:1978-86.

(16) About E.coli. Non-O157 STEC.n.d.; Available at: http://www.aboutecoli.com/non_o157_STEC/\#.ViSQi3pViko

(17)_Vancouver Coastal Health. Food safety update. 2013; Available at: https://www.vch.ca/media/Food-Safety-Update2013.pdf

(18) Canadian Food Inspection Agency. CFIA investigation into XL Foods Inc. 2013; Available at:

http://www.inspection.gc.ca/food/informationfor-consumers/food-safety-investigations/xlfoods-inc/investigation/eng/1347937722467/13479378182 $\underline{75}$

(19) Government of Canada. Report of the independent investigator into the 2008 Listeriosis outbreak. 2009; Available at: http://www.cpha.ca/uploads/history/achievement s/09-lirs-rpt_e.pdf 
(20) BC Center for Disease Control. Guidelines for sous vide cooking safety in British Columbia. 2004; Available at: http://www.bccdc.ca/NR/rdonlyres/1692F859D7A8-4B19-8841C8418DEF412C/0/SVGuidelines_FinalforWeb.p $\underline{\mathrm{df}}$

(21) Canadian Food Inspection Agency. Guidance document repository Annex D: Cooking time/temperature table. 2013; Available at: http://www.inspection.gc.ca/food/meat-andpoultry-products/manual-of-procedures/chapter4/annexd/eng/1370527526866/1370527574493\#t1

(22) Baldwin DE. Sous vide cooking: A review. International Journal of Gastronomy and Food Science 2012;1(1):15-30.

(23) Statistics Canada. Revenue up for food service industries, 11-402-X. 2013; Available at: http://www.statcan.gc.ca/pub/11-402x/2010000/chap/services/services01-eng.htm

(24) Technomic. Packaging can make or break a takeout meal. 2012; Available at: https://blogs.technomic.com/packaging-canmake-or-break-a-takeout-meal/

(25) BC Center for Disease Control. Re-usable takeout containers. 2013; Available at: http://www.bccdc.ca/NR/rdonlyres/D21377158D4F-4A20-B777-

5F808F6A7CAC/0/Reuseabletakeawaycontainer s1.pdf

(26) Government of Western Australia. Restaurant taking home leftover food (doggy bags). 2015; Available at: http://www.commerce.wa.gov.au/sites/default/fil es/atoms/files/takinghomeleftoversrestaurants.pd f

(27) Society Promoting Environmental Conservation. Sustainable to-go food containers. 2013; Available at: http://www.spec.bc.ca/Resources/Documents/Wa ste/G2G/Green $\% 202 \% 20 \mathrm{Go} \% 20$ Report $\% 20 \mathrm{FIN}$ ALFINAL.pdf

(28) Tokiwa Y, Calabia BP, Ugwu CU, Aiba S. Biodegradability of plastics. Int J Mol Sci 2009; 10(9): 3722-3742

(29) Canadian Cancer Society. Microwaves and plastic containers. n.d.; Available at: http://www.cancer.ca/en/prevention-andscreening/be-aware/cancer-myths-andcontroversies/microwaves-and-plasticcontainers/?region $=$ on
(30) Government of Canada. Justices law website: Food and Drugs Act. 2014; Available at: http://laws-lois.justice.gc.ca/eng/acts/F27/FullText.html

(31) Jekanowski MD, Binkley JK, Eales J. Convenience, accessibility, and the demand for fast food. Journal of Agricultural and Resource Economics 2001; 26(1): 58-74.

(32) Heacock H., Karakilic V. Research Methods Module 4: Research Design \& Data Collection [unpublished lecture notes]. British Columbia Institute of Technology; notes provided at lecture given 2015 September 25.

(33) Heacock H., Karakilic V. Research Methods Module 5: Inferential Statistics (Overview of Inferential Statistics: Regression and Correlation) [unpublished lecture notes]. British Columbia Institute of Technology; notes provided at lecture given 2015 November 5.

(34) Food Premise Regulation, B.C. Reg. 210/99, O.C. 774/99 [Internet]. 2013 Feb 22 [cited 2016 February 29]. Available from http://www.bclaws.ca/Recon/document/ID/freesi de/11_210 99

(35) BC FOODSAFE. FOODSAFE Level 1, Participate Workbook. Canada: Province of British Columbia; 2014.

(36) Canadian Food Inspection System Implementation Group. Food Retail and Food Services Code. 2004; Available at http://foodsafe.ca/resources/Food_Services_Cod e2004.pdf

(37) Hamrick K, Andrews M, Gutherie J, Hopkins D, McClelland K. How much time do Americans spend on food? United States Department of Agriculture. Economic Research Services 2012;86

(38) Livestrong.com. What is a better insulator: Paper, Glass, Plastic, or Styrofoam?. 2015; Available at:

http://www.livestrong.com/article/345286-whatis-a-better-insulator-paper-glass-plastic-orstyrofoam/

(39) Reddit-AskCulinary. How hygienic is the Vietnamese raw beef pho.2014; Available at: https://www.reddit.com/r/AskCulinary/comment $\mathrm{s} / 2 \mathrm{gcx} 9 \mathrm{c} / \mathrm{how}$ hygienic_is_the_vietnamese_raw beef_pho/

(40) Yahoo Answers. Is pho (Vietnamese soup) suppose to be served with raw beef?2008 https://ca.answers.yahoo.com/question/index?qid $=20080811152925 \mathrm{AAdO} 41 \mathrm{f}$ 
(41) Food Safety News. Japan Cracks Down on Raw Meat Dishes. 2011; Available at:

http://www.foodsafetynews.com/2011/10/japancracks-down-on-raw-meat-

dishes/\#.VtozH5wrJWJ

(42) Ethelberg S, Sorensen G, Kristensen B,

Christensen K, Krusell L, Hempel-Jorgensen A,

et al. Outbreak with multi-resistant Salmonella

Typhimurium DT104 linked to carpaccio,

Denmark, 2005. Epidemiology and Infection

2007; 135(6):900-907.

(43) U.S. Food and Drug Administration.

Microbiological Safety Evaluations and

Recommendations on Sprouted Seed.1999;

Available at:

http://www.fda.gov/Food/GuidanceRegulation/G uidanceDocumentsRegulatoryInformation/Produ cePlantProducts/ucm078789.htm\#foodborne

(44) Foodsafety.gov. Sprouts: What you should know. n.d.; Available at:

http://www.foodsafety.gov/keep/types/fruits/spro uts.html 